\title{
SOBRE O INFINITO NA FILOSOFIA DA VERDADE DAS CIÊNCIAS FORMAIS
}

\author{
ABOUT INFINITY IN THE PHILOSOPHY OF TRUTH OF FORMAL SCIENCES
}

Mateus de Carvalho Maia ${ }^{1}$

(matrix.maia08@gmail.com)

\section{RESUMO}

A verdade lógica muitas vezes acaba por receber um patamar epistêmico, ou mesmo metafísico, superior a outros tipos de verdade, justamente por ser considerada mais básica do que essas outras, sendo utilizada, inclusive, como um tipo de pedra de toque - fazendo-se uma alusão puramente metafórica à Kant - para a fundamentação dessas verdades. De todo modo, nada disso garante que a verdade lógica, por sua vez, encontre-se totalmente estabelecida e livre de fantasmas, afinal, até mesmo a própria noção de verdade lógica é algo ainda a ser analisado. Este texto tem por finalidade, portanto, investigar o papel fundacional da verdade lógica e estudar algumas das questões que surgem nesse processo.

Palavras-chave: Verdade. Semântica. Infinitude. Tarski. Linguagem.

\begin{abstract}
Logical truth frequently receives a superior epistemic or even metaphysical status when compared to other kinds of truth, precisely for being considered more fundamental than the others. It is even utilized as a touchstone - we establish here a purely metaphorical allusion to Kant - for the grounding of such truths. None of these things grants that logical truth is fully established and free of ghosts, after all, even the own notion of logical truth is something to be analyzed. This text, therefore, aims to look into this foundational role played by logical truth and inquire into some of the questions that emerge in this process.
\end{abstract}

Keywords: Truth. Semantics. Infinity. Tarski. Language.

\section{INTRODUÇÃO}

A noção de verdade sempre ocupou papel central na lógica. As investigações fundacionais contemporâneas, iniciadas por Gottlob Frege na segunda metade do século XIX,

\footnotetext{
${ }^{1}$ Graduando em Filosofia pela Universidade de Brasília (UnB).

CV Lattes: http://lattes.cnpq.br/6706801738148908.

ORCID: https://orcid.org/0000-0002-9506-5346.
} 
podem ser vistas como uma tentativa de fundamentar a verdade matemática na verdade lógica, presumivelmente mais bem compreendida. Contudo, os paradoxos lógicos, principalmente o Paradoxo do Mentiroso e o Paradoxo de Russell, mostram que a noção de verdade lógica não está livre de dificuldades. Há várias questões a serem tratadas, e o presente texto tem como objetivo investigar algumas delas, explicadas a seguir.

A primeira questão que podemos colocar diz respeito à própria formulação da noção de verdade em um sistema lógico formal. Como consequência do Paradoxo do Mentiroso, há sérias limitações para a predicação da verdade ao nível da linguagem-objeto. Em termos mais precisos, uma linguagem-objeto consistente não pode definir, ao mesmo tempo, sua predicação da verdade e a autorreferência das sentenças. A proposta-padrão, devida a Tarski, para lidar com essa limitação é a introdução da metalinguagem e o entendimento da predicação da verdade em um metanível. Nesse caso, a própria predicação da verdade leva a uma hierarquia infinita de metalinguagens: o entendimento da verdade de uma sentença da linguagem-objeto é dado por uma sentença da metalinguagem, cuja verdade é entendida em uma metametaliguagem, ad infinitum (isto é, cai-se em um regresso ao infinito).

Da proposta-padrão sobre a formulação da verdade em termos de metalinguagem segue a segunda questão que nos interessa: a formulação de verdade na lógica leva a uma hierarquia infinita de metalinguagens. Seria essa infinitude da lógica, ela própria, de natureza lógica? A infinitude nas concepções lógicas de verdade é justamente o ponto em que este texto almeja culminar. O objetivo é desenvolver essa questão tanto técnica quanto conceitualmente e não somente buscar entendê-la, como também investigar o peso de uma possível medida paliativa.

\section{DESENVOLVIMENTO}

A questão da verdade está ligada de modo muito íntimo à própria filosofia, desde seus primórdios até as investigações contemporâneas. Em diversos momentos da tradição filosófica, questões referentes à natureza da verdade, ao acesso a verdade, à realidade da verdade foram postas em pauta, evidenciando-se ainda mais como qualquer investigação de cunho genuinamente filosófico requer uma prévia concepção do que é a própria verdade; afinal, ao se discorrer sobre qualquer assunto, existe algum critério para separar o que é coerente do que não é, critério esse que poderia ser associado à verdade. 
Hegel, em Introdução à história da filosofia, diz que "A filosofia é a ciência objetiva da verdade” (HEGEL, 1988, p. 336); em seguida, continua o filósofo: “A palavra verdade é justamente o que assusta aqueles que na história da filosofia buscam apenas opiniões ou estão persuadidos de que nela nada mais se pode encontrar além de opiniões” (HEGEL, 1988, p. 336). Sem entrar em grandes detalhes do que seria isso que aqui foi chamado de 'investigação filosófica', poder-se-ia, sem muitos pesares, afirmar que um dos pré-requisitos mínimos para uma investigação merecer o adjetivo de filosófica seria a mesma compactuar com algum tipo de definição do que é verdade. Tal pré-requisito é relevante pois até mesmo para investigações acerca da própria verdade é necessária alguma concepção prévia da mesma, que tem como papel legitimar o discurso sobre, no caso, a verdade - isto é, parece difícil falar de verdade, ou sobre qualquer coisa, sem já apresentar um esclarecimento acerca do que é, por fim, 'verdade'.

A filosofia, portanto, como ciência objetiva da verdade, se não em seu foco, tem em sua alma e essência a questão da verdade, ou seja, verdade é indissociável de filosofia. Por outro lado, tal afirmação não deve ser entendida como significando que a filosofia é aquilo que detém a verdade, mas como aquilo que busca aproximar-se da verdade. A filosofia e o filósofo são aquilo e aquele que se preocupam com a verdade, que se comprometem com ela. É possível observar esse papel básico, isto é, fundacional, que a filosofia tem em relação ao conhecimento: o papel de lidar com a sustentação que garante o bom desenvolvimento de inúmeras áreas do saber.

De todo modo, neste instante um questionamento torna-se tão pertinente que não pode ser ignorado: ora, e onde se situa a fundamentação da verdade? Essa questão não somente é natural como muito relevante para o andamento do que aqui se inicia, afinal, estabeleceu-se a relação entre filosofia e verdade, além de se ter apresentado a filosofia como responsável pela fundamentação de diversas áreas do saber. É crucial, então, que saibamos como se dá esse processo, ou melhor, como se dá a fundamentação da verdade que tem o papel de fundamentar outros tipos de verdade. Voltemo-nos, enfim, a algo como a filosofia da verdade, ou, por assim dizer, voltemo-nos para a lógica.

Sem dúvida é algo muito natural, em diversos níveis de discurso, associar 'verdade' também a 'lógica'. O próprio Gottlob Frege, no célebre texto Der Gedanke, comumente traduzido por The thought [O pensamento], logo na primeira frase afirma que, "Just as 'beautiful' points the way for aesthetics and 'good' for ethics, so do words like 'true' for logic" (FREGE, 1956, p. 325). Frege, portanto, defende que é a verdade 
aquilo que assinala o objeto da lógica, fazendo com que a verdade, desse modo, seja nada mais, nada menos do que o grande assunto da lógica. Frege completa: "To discover truths is the task of all sciences; it falls to logic to discern the laws of truth" (FREGE, 1956, p. 325). Nesse ponto, estabelece-se a relação entre lógica, filosofia e alguma área do conhecimento: nessa concepção, a filosofia, tal como foi defendido, tem sobre seus ombros a árdua tarefa de buscar uma fundamentação para algum campo de estudo; a lógica, por sua vez, tem como objetivo designar o processo geral em que se estabelece uma verdade. À vista disso, assim como a lógica possui uma associação quase inevitável com a verdade, é indissolúvel sua necessidade para qualquer tipo de filosofia.

No entanto, falar de leis da verdade em muitos casos pode gerar um desentendimento significativo no que se refere à ontologia da visão de mundo por trás da lógica que se pretende desenvolver. Frege enfatiza a distinção que a palavra 'lei' apresenta nesse contexto, defendendo que em um primeiro sentido ela poderia ser entendida como um conjunto de normas, de prescrições que devem ser obedecidas. O filósofo dá o exemplo das leis morais e jurídicas: nem sempre o que acontece está em conformidade com elas. Quanto ao segundo sentido, o pensador o associa, por meio de uma analogia, às leis da natureza, afirmando que são generalizações dos acontecimentos naturais, os quais, por outro lado, estão sempre em concordância, diferentemente do que ocorre no sentido anterior.

Seria justamente nessa segunda concepção que se poderia falar de leis do pensamento. Isso, porém, pode gerar uma confusão: Frege ateve-se a esse ponto, e afirmou, ainda em The thought, que

People may very well interpret the expression 'law of thought' by analogy with 'law of nature' and then have in mind general features of thinking as a mental occurrence. A law of thought in this sense would be a psychological law. And so they might come to believe that logic deals with the mental process of thinking and with the psychological laws in accordance with which this takes place. That would be misunderstanding the task of logic, for truth has not here been given its proper place. (FREGE, 1956, p. 325)

A analogia que Frege propõe pode nos levar a pensar que a lógica lida com o modo como as coisas acontecem; falando de forma clara e objetiva: uma lógica, nesses moldes, lida com a maneira com que as pessoas pensam.

Evidentemente, parafraseando Frege, isso seria desconhecer o papel da lógica. O objetivo da lógica não é descrever como ocorre o processo mental, o qual, sem fazer alusão ao significado técnico que a palavra possui na filosofia de 
Frege, chamamos de pensamento ${ }^{2}$. A maneira com que as pessoas pensam é variante e muitas vezes contraditória, predicado esse que em um âmbito clássico não é muito desejável. Podese dizer portanto que a lógica não descreve como se dá o pensamento, como se dá o raciocínio, como se dá o juízo das pessoas, mas sim como seria tudo isso caso estivesse em concordância com algum tipo de lei da verdade de que decorrem prescrições para pensar, julgar, raciocinar - o que determina, de acordo com Frege, as leis do pensamento. Simplesmente citando o filósofo: "Here of course it is not a matter of what happens, but of what is" (FREGE, 1956, p. 325).

Tendo agora realizado a tarefa de despsicologizar a lógica, podemos nos ater a outro ponto que precisa ser colocado em pauta, a própria questão por trás do problema da verdade com que estamos buscando lidar. É necessário delimitar o assunto para podermos finalmente adentrá-lo.

\subsection{O problema da verdade}

É preciso que fique claro o que queremos dizer com 'o problema da verdade' e, antes de tudo, o que temos em mente ao falarmos de 'lógica'. Falou-se muito em lógica e comentaram-se características da mesma, além de se terem citado textos de renomados autores que falavam dela. O que não está claro ainda, e é crucial que fique, é qual lógica almejamos analisar, isto é, qual lógica será o centro de nossas investigações fundacionais. Tal questionamento é evidentemente relevante, pois, no atual século, falar de 'lógica' sem especificar o que tal palavra denota é muito pouco. Qualquer iniciado no assunto sabe que, quando Bertrand Russell fala de lógica e David Lewis fala de lógica, existe uma considerável discrepância entre os assuntos abordados por eles. Já que nosso objetivo é lidar com algum problema da verdade - termo que ainda se mostra obscuro - tendo como ambiente a lógica, precisamos, portanto, deixar claro o que estamos chamando de 'lógica'.

De todo modo, ao nos questionarmos acerca de qual lógica estamos colocando em pauta, já é proposto que se sabe evidentemente o que é uma lógica. Sendo assim, devemos, como passo propedêutico, responder às questões: o que é uma lógica? Qual é a essência de 'lógica'? Não é preciso muito tempo refletindo para tornar-se notório que 'lógica', isoladamente, é uma palavra polissêmica, isto é, pode ser utilizada em diversos contextos, além de em muitos deles denotar coisas bastante distintas. Definiremos 'lógica',

\footnotetext{
${ }^{2} \mathrm{O}$ que Frege chama de 'pensamento' hoje é entendido, em seu sentido técnico, como proposição.
} 
tendo como referência o trabalho de Jean-Yves Béziau, em particular o artigo Universal logic (BÉZIAU, 1994, p. 84), como:

$$
L=\langle F, \vdash\rangle
$$

Ou seja, uma lógica $L$ é um par $L=\langle F, \vdash\rangle$, tal que ' $F$ ' é um conjunto de fórmulas e ' $\vdash$ ' é uma relação de consequência. É claro que o que se almeja com uma boa definição, ao menos em grande parte dos casos, é que a mesma seja tal que capture uma ou algumas coisas e descarte todo o resto. O que se ganha com a definição acima é o esclarecimento sobre a natureza daquilo com que estamos lidando ao falarmos de uma lógica, fazendo com que qualquer outra coisa que 'lógica' possa denotar em outros discursos seja deixada de lado. Perceba que usamos um artigo indefinido ao comentar nossa definição, porque não estamos falando de uma lógica em particular, mas sim de qualquer sistema formal.

A questão agora passa a ser, tal como previsto, qual lógica é aquela com que pretendemos lidar. A quantidade de sistemas formais, isto é, de lógicas em pleno século XXI é quase pragmaticamente não enumerável. Podem-se encontrar lógicas com distinções que variam desde coisas muito pontuais até algumas totalmente diferentes; seus fins são com frequência também discrepantes, diga-se de passagem. Exatamente por isso, todo o cuidado que estamos tendo é crucial para se evitarem problemas acarretados por singelas confusões nesta parte preliminar. Deixemos claro que lidaremos exclusivamente com a lógica clássica. O problema da verdade que colocaremos em pauta se dará, portanto, por intermédio da lógica clássica.

De todo modo, pergunta-se: ora, mas por que a lógica clássica? A resposta é muito mais simples do que se imagina. Apesar de, tal como já foi defendido, ser algo bastante duvidoso falar de 'a lógica', é razoável o entendimento de que a lógica clássica é a mais bem estabelecida, justamente por ser aquela à qual a tradição, desde Aristóteles até Gödel e em diante, mais se dedicou e ateve-se em suas investigações. É esse peso que nos interessa; faz sentido querer discutir o problema da verdade no ambiente mais utilizado e organizado para tal. O que é relevante, aqui, são o peso e o aparente patamar de estabilidade que a lógica clássica possui em relação às outras lógicas.

Além do mais, assim como argumenta Newton da Costa em Ensaio sobre os fundamentos da lógica (DA COSTA, 1994, p. 77), a lógica clássica, estabelecida e postulada de forma bastante rigorosa - principalmente considerando-se a época - 
por Aristóteles, advém de uma concepção metafísica de mundo, a qual estabelece certos pontos fundamentais que parecem capturar o entendimento ontológico de verdade que aqui se almeja desenvolver. A visão metafísica de mundo e, por conseguinte, de verdade que Aristóteles reflete em sua lógica é algo para com o qual, neste momento de intuições prévias, desejaríamos uma aproximação.

Agora que sabemos onde estamos falando, isto é, na lógica clássica, é necessário esclarecer o que temos em mente ao falar de 'o problema da verdade' - é preciso que respondamos à questão: qual é o problema da verdade? Da mesma forma que 'lógica' é uma palavra polissêmica, 'verdade' também apresenta um significado bastante ambíguo e, além do mais, não nos interessa neste contexto algumas das muitas coisas que se têm em mente com o uso de tal palavra. O problema da verdade que nos interessa não é qualquer um.

Relembrando o que Frege (1956, p. 325) disse, podemos entender como papel de toda ciência, de forma geral, descobrir verdades. 'Verdade' está presente em praticamente qualquer área do saber, e em cada uma delas 'o problema da verdade' pode denotar algo distinto, podendo se dar em um âmbito epistemológico ou mesmo pragmático. Todavia, nosso foco é o âmbito semântico, isto é, aquele que se refere ao significado. É válido ressaltar, ainda, que essas verdades já pressupõem, mesmo que inconscientemente, o que significa 'verdade', e é precisamente esse o nosso ponto: o que nos interessa é a relação-verdade, uma relação que se dá, de forma assimétrica, entre o que se diz e o que é o caso. Em outras palavras, a verdade a que nos ateremos é uma propriedade de frases a qual postula que certas frases são verdadeiras sempre que estão de acordo com o mundo. Entretanto, pergunta-se imediatamente: e o que é esse mundo? Que tipo de verdade semântica é essa que se dá, de alguma forma, pelo mundo? Deve-se, então, analisar qual é a concepção de mundo por trás da lógica - no caso, da lógica clássica de primeira ordem.

Enfatizando o que já foi dito, nossa análise sobre a verdade é uma análise sobre a concepção semântica de verdade ao nível do discurso, e por isso faz sentido dizer que a verdade se aplica a frases. Deve ficar claro que a verdade que temos em mente é uma verdade em um âmbito formal; pode-se então dizer que é a verdade lógica que nos interessa. E por que a verdade lógica? Por que esse tipo de verdade, de que ainda se tem somente uma noção intuitiva e ingênua, apresenta-se em um patamar superior a algum outro? A resposta, de certo modo, já foi dada: a verdade lógica nos interessa por sua característica de fundamentação, por ser aquela que em princípio garante as outras verdades. Basicamente, estamos fazendo uso da clássica sugestão cartesiana de se garantir um alicerce seguro para 
com isso se permitir o bom desenvolvimento dos demais conhecimentos. Voltemo-nos, finalmente, para o problema da verdade lógica.

\subsection{O problema da verdade lógica}

Alguém poderia argumentar que, na realidade, a verdade lógica não merece esse patamar privilegiado e que, quando muito, é um singelo jogo formal com símbolos. O grande problema nessa posição está no simples fato de se usar um argumento. Em um contexto no qual não existe nenhum tipo de verdade lógica para legitimar alguma inferência em um discurso, como é possível falar de argumentos? Perceba que não estamos falando de lógica clássica ou lógica não clássica; na realidade, sequer estamos nos referindo a alguma concepção mais rigorosa de lógica, tal como foi apresentado linhas acima. O ponto é que para qualquer discurso, primordialmente para os discursos científico e filosófico, é necessário o entendimento de um patamar anterior e fundacional para que faça sentido, antes tudo, falar de argumentos e conclusões. Evidentemente, essa posição radical com relação à verdade lógica, seja qual for a lógica, é algo muito árduo de se defender em um âmbito filosófico.

Por outro lado, nosso objetivo aqui não é afirmar categoricamente que a verdade lógica, em particular a verdade da lógica clássica, deve ser a responsável por exercer o papel de pedra fundamental para o desenvolvimento do conhecimento. $\mathrm{O}$ que se pretende com o que se segue é, partindo do fato de que a verdade lógica possui um caráter fundacional - sem falar em mais ou menos - em relação a outras coisas, buscar entender como é possível capturar formalmente tudo o que a intuição nos dá quanto à verdade, e questionar o peso que esse processo pode acarretar. A tentativa de fundamentar a verdade matemática na verdade lógica já expõe o papel básico ${ }^{3}$ que grandes pensadores, como Frege, acreditavam ser devido à verdade lógica.

Durante toda a tradição filosófica, e mesmo antes dessa compreensão, diversos pensadores buscaram apresentar explicações para suas descobertas nos campos da matemática. Um dos primeiros filósofos a se dedicar de tal forma e que mesmo hoje merece ainda ter seus avanços estudados é o já citado Frege.

Toda a proposta de fundamentação da matemática de Frege perpassa um conceito muito simples: desfazer a separação tradicional entre Lógica e matemática. ${ }^{4}$ Durante boa parte

\footnotetext{
${ }^{3}$ Palavra essa que, mais uma vez, não deve ser entendida como significando 'simples', mas sim 'fundamental' . ${ }^{4}$ Perceba que estamos, nesse momento, escrevendo 'Lógica' com letra maiúscula, pelo simples fato de que aqui não estamos nos referindo a alguma lógica em particular, mas sim à noção geral, e única, de Lógica.
} 
da história da filosofia antes de Frege, propagou-se uma discrepância muito grande entre matemática e Lógica, o que é claramente defendido por Kant, por exemplo, quando diz que um juízo matemático é sintético - cria coisas - e a priori - está antes da experiência -, enquanto um juízo lógico é analítico - simplesmente um desdobramento do que ali já estava e a priori, evidentemente. Entretanto, a postura adotada por Frege, conhecida hoje como logicista, defende que toda a matemática pode ser reduzida à Lógica, o que inevitavelmente colocaria fim a essa separação. Porém, um dos motivos de até grandes filósofos como Kant acreditarem em tal diferença é que, em seu tempo, a lógica disponível não era suficiente para fundamentar a matemática ${ }^{5}$, afinal, não seria nem um pouco razoável acreditar que toda a matemática poderia ser reduzida aos silogismos, os quais basicamente resumiam a lógica disponível naquele momento. Assim, para Frege prosseguir com sua proposta, seria necessário que apresentasse uma lógica capaz de fundamentar a matemática - foi o que ele fez e, por isso, diga-se de passagem, é considerado o pai da lógica formal moderna.

Frege apresentou uma teoria escrita em lógica de primeira ordem, com pertencimento e igualdade, que de fato, a partir de seus axiomas, tornou possível deduzir toda a aritmética, o que era o plano original do filósofo. Entretanto, um problema muito grave surgiu no momento em que Bertrand Russell demonstrou que o projeto logicista de Frege era inconsistente, isto é, contraditório. Considerando-se que estamos em um contexto de lógica clássica, isso acarretou inevitavelmente a trivialização do sistema: de fato a teoria de Frege provava a aritmética, mas provava também qualquer outra coisa, inclusive a negação de todo teorema.

O problema se dá na Lei Básica $V$ da teoria de Frege, a qual consistia nos dois princípios a seguir ${ }^{6}$ :

i) Princípio da Excepcionalidade: $x=y \leftrightarrow \forall z(z \in x \leftrightarrow z \in y)$;

ii) Princípio da Abstração: $\exists x \forall z(z \in x \leftrightarrow P z)$.

Russell aponta que, por meio do Princípio da Abstração, é possível derivar uma contradição, o que ficou conhecido no decorrer da história como o Paradoxo de Russell. Antes de darmos continuidade ao assunto, deve-se esclarecer o que entendemos por 'paradoxo'. Existem várias formas de se definir o que é um paradoxo, e a maneira de que faremos uso é dizer que um paradoxo é o que se origina quando, a partir de premissas

\footnotetext{
${ }^{5}$ É válido ressaltar que a matemática já exercia esse papel de fundamentação das demais ciências. Torna-se, portanto, difícil imaginar algo ainda mais fundacional que a própria matemática.

${ }^{6}$ A teoria de Frege não utilizava a linguagem em questão; trata-se de uma releitura moderna equivalente a trabalho original exposto por Frege.
} 
intuitivas, razoáveis, conclui-se algo não intuitivo ou mesmo um absurdo. Devem-se destacar tais coisas para que fique clara, por exemplo, a diferença entre um paradoxo e uma contradição, já que, ao menos para este contexto, é relevante que as naturezas dessas duas coisas sejam distintas.

Tendo em mente essa definição, pode-se observar como o Princípio da Abstração de fato captura, em um primeiro olhar, a intuição de que a matemática é um discurso sobre conceitos e extensões de conceitos. É notório que uma das leituras mais óbvias do princípio em questão, isto é, $\exists x \forall z(z \in x \leftrightarrow P z)$, equivale a dizer que, dado um conceito, tem-se a extensão desse conceito. O grande questionamento imposto por Russell é: todo conceito possui extensão?

O que Russell faz então é definir a propriedade ' $P$ ' como ' $z \notin z$ ', isto é, propriedade de não pertencer a si mesmo, não predicar de si próprio. Por fim, obtém-se:

$$
\exists x \forall z(z \in x \leftrightarrow z \notin z)
$$

A pergunta que inevitavelmente se faz é: $z$ pertence a si mesmo? A resposta, tal como aponta Russell, é:

$$
(z \in z \leftrightarrow z \notin z)
$$

Poder-se-ia argumentar que uma das questões por trás do Paradoxo de Russell, evidenciado acima, é a não distinção entre conceito e extensão do conceito. O Princípio da Abstração garante que, dado um conceito, pode-se construir sua extensão. O que acabamos de observar é que isso não é o caso: não é o caso que todo conceito pode ter extensão. $\mathrm{O}$ entendimento das duas coisas como equivalentes tem em sua base esse erro muito claro, até mesmo em âmbitos não formais. A extensão de 'cadeira' é exatamente o conjunto, a classe de todas as cadeiras; de todo modo, o conceito de 'cadeira' não é, ele próprio, uma cadeira. $\mathrm{O}$ mesmo vale para conceitos como 'azul', 'homem', dentre outros.

Tal questão culmina no fim do projeto fregeano de fundamentação da matemática. Isso não quer dizer que Frege estava errado em acreditar que a matemática segue princípios lógicos, mas sim que isso não se dá de forma a se terem seus princípios claros, evidentes e intuitivos de acordo com a própria prática da matemática. Apesar de sua falha tentativa, não se pode dizer que o projeto de Frege, fundamentar a verdade 
matemática na verdade lógica, é impossível. Todas as outras escolas de fundamentação da matemática farão uso do progresso fregeano e tentarão lidar com suas falhas. E falar em superar a falha de Frege, exposta por Russell, é entender que de algum modo é necessário impor restrições a certas extensões.

Portanto, apesar de, tal como foi observado, Frege falhar e sua teoria ser contraditória, o avanço que Frege proporcionou não pode ser deixado de lado. A estratégia-padrão para se lidar com o Paradoxo de Russell, entendendo a problemática dos conceitos e extensões, é substituir o Princípio da Abstração em sua forma geral por instâncias particulares do mesmo, como é o próprio caso do axioma da compreensão/separação ${ }^{7}$ :

$$
\forall y \exists x \forall z(z \in x \leftrightarrow z \in y \wedge P z)
$$

Perceba que esse novo axioma, com o simples acréscimo da cláusula ' $z \in y^{\prime}$ em conjunção com ' $P z$ ', não é mais contraditório, pois agora, a partir de um conjunto dado, podem-se separar partes dele por intermédio de um conceito, o que advém da questão de que é necessário o entendimento de uma hierarquia de pertencimento ao se falar de conjuntos, ou seja, é necessária uma restrição. Não obstante, ainda pode-se argumentar, nos moldes de Graham Priest em In contradiction (PRIEST, 2006, p. 9), que tal coisa de modo algum resolve o paradoxo - afinal, o Princípio da Abstração ainda é intuitivo e, quando admitido, acarreta uma contradição. Restringir o axioma seria jogar a sujeira para debaixo do tapete, em sua concepção. De todo modo, também é honesto argumentar que as intuições falham e que o problema é gerado por um mau entendimento de certos princípios, como foi apontado ao se levantar o debate sobre conceitos e extensões.

O formalismo, por sua vez, também é uma corrente de filosofia da matemática que tenta compreender a verdade matemática como verdade lógica, ou melhor, como demonstração lógica. Esse movimento visou à inversão da ordem natural de fundamentação das disciplinas matemáticas. Durante boa parte da história, a geometria exercia o papel fundacional em relação à matemática pura, papel esse que para o formalismo deveria ser dado à aritmética. ${ }^{8} \mathrm{O}$ formalismo considera que a demonstração deve ser dada em um âmbito puramente formal, sem interpretações. Assim, uma demonstração rigorosa é uma construção ostensiva do objeto obtendo a propriedade em questão. $\mathrm{O}$ formalismo, portanto, abole a

\footnotetext{
${ }^{7}$ Presente em praticamente qualquer formulação-padrão da teoria Zermelo-Fraenkel.

${ }^{8}$ Diferentemente do que é feito, inclusive hoje, em cursos introdutórios, como é o caso de Cálculo 1, em que ainda se faz uso de demonstrações geométricas, tal como a demonstração do Limite Trigonométrico Fundamental.
} 
diferença entre demonstração lógica e demonstração matemática. 'Verdade', para um formalista, é demonstração lógica em algum sistema formal.

O formalismo, como corrente que visa a eliminar a referência a objetos abstratos, faz a identificação de 'verdade' com 'demonstração'. Hilbert, um dos maiores nomes do movimento, impõe inclusive apenas duas cláusulas para um sistema formal ser bom o bastante para fundamentar a matemática:
i) Consistência;
ii) Completude.

A questão da verdade, para um formalista nos moldes de Hilbert, somente faz sentido nessas condições. 'Verdade' é apenas demonstração em um sistema formal, e 'verdadeiro' é tudo aquilo que é demonstrável nesse sistema. O problema deveria passar, então, para a formulação de um sistema formal que satisfizesse às condições (i) e (ii) de Hilbert ${ }^{9}$, a fim de que a fundamentação da matemática se mostrasse ela mesma satisfeita. Entretanto, todo o programa de Hilbert é derrubado quando o austríaco Kurt Gödel, em 1931, prova dois teoremas que ficaram conhecidos como os Teoremas da Incompletude de Gödel. Podemos enunciar os teoremas da seguinte forma:

- Primeiro teorema: Se ' $S$ ' é consistente, então ' $S$ ' é incompleto;

- Segundo teorema: Se ' $S$ ' é consistente, então a sentença que expressa a consistência de ' $S$ ' é indemonstrável em ' $S$ '. ${ }^{10}$

Gödel, portanto, não somente demonstra que não existe um sistema formal nos moldes do que almejava Hilbert; demonstra também que nunca poderá existir uma teoria forte o bastante para fundamentar a matemática, que satisfaça às condições de consistência e completude - o que, tal como anunciado, crava o fim de qualquer tipo de postura próxima ao programa de Hilbert, e evidencia ainda mais o problema da verdade que surge com a identificação da mesma com mera demonstração formal.

No já citado Ensaio sobre os fundamentos da lógica, Newton da Costa (1994, p. 94) argumenta que uma das principais consequências filosóficas dos Teoremas de Gödel é o fato

\footnotetext{
${ }^{9}$ Hilbert inclusive defendeu que a formulação de um sistema formal não deveria ficar restrita ao âmbito da matemática. O filósofo acreditava que a axiomatização de ciências como a física deveria ter papel central nos trabalhos futuros dos pesquisadores da área.

${ }^{10}$ Sendo ' $S$ ' uma teoria axiomática qualquer recursivamente enumerável.
} 
de que a noção de verdade lógica, fora do que o autor chama de 'lógica-elementar' basicamente a lógica clássica de primeira ordem -, não se deixa codificar e sistematizar de maneira sensata, parafraseando o próprio filósofo.

Caímos em outro problema da verdade. Depois de termos observado as relações que a verdade lógica apresenta com esses outros tipos de verdade, devemos nos ater à própria verdade lógica, essa que é entendida por muitos como possuindo um patamar privilegiado e mais fundamental. Voltemo-nos, então, para a questão da concepção de mundo por trás da lógica clássica de primeira ordem: 'verdade' é um atributo de frases, é uma relação entre frase e mundo. É necessário definir o que será uma fórmula de primeira ordem, o referente das frases, e uma estrutura, ou seja, o referente do mundo, no âmbito da lógica clássica de primeira ordem.

\section{VERDADE LÓGICA}

\subsection{Fórmulas}

Precisamos compreender dois ingredientes para falar de 'verdade':

$$
\mathfrak{a}(\varphi)=\text { valor de verdade }
$$

Dada uma fórmula $\varphi$ e uma estrutura $\mathfrak{a}$, que se dão em uma mesma linguagem $l$, podese finalmente falar em valor de verdade para $\varphi$. Iniciemos pelo primeiro ingrediente essencial - as fórmulas, referente das frases no contexto da lógica clássica de primeira ordem. Ora, mas o que são fórmulas? De modo bastante natural e intuitivo, podem-se entender preliminarmente fórmulas como sequências de símbolos que correspondem a sentenças gramaticalmente bem formadas da língua natural em questão. A pergunta que se segue é: quais símbolos? É preciso estabelecer a gramática de nossa linguagem e, para tal, devemos nos ater à distinção entre símbolos lógicos e símbolos não lógicos.

A diferença crucial entre um símbolo lógico e um não lógico é o fato de os símbolos lógicos manterem a mesma interpretação sempre. Tradicionalmente, quando observamos uma sentença como: $\forall x(P x \rightarrow Q x)$, sabemos que os símbolos referentes aos pronomes e aos predicados - no caso, respectivamente, ' $x$ ', ' $P$ ' e ' $Q$ ' - em cada estrutura 
denotam algo distinto e, por conseguinte, significam coisas variantes em cada contexto. Por outro lado, os símbolos dos quantificadores e os símbolos dos conectivos - respectivamente, ' $\forall$ ' e ' $\rightarrow$ ' - possuem significado-padrão em toda e qualquer estrutura dessa mesma lógica.

A gramática, então, constará, primeiramente, dos símbolos não lógicos:

- Símbolos para desambiguação (parênteses): (,)

- Nomes para indivíduos:

i) Pronomes: $x^{1}, x^{2}, x^{3}, x^{4}, \ldots$

ii) Nomes próprios (constantes) $: a^{1}, a^{2}, a^{3}, a^{4}, \ldots$

- Nomes para predicados:

$$
\begin{aligned}
& A_{1}^{1}, A_{1}^{2}, A_{1}^{3}, A_{1}^{4}, \ldots \text { (unários) } \\
& A_{2}^{1}, A_{2}^{2}, A_{2}^{3}, A_{2}^{4}, \ldots \text { (binários) } \\
& A_{3}^{1}, A_{3}^{2}, A_{3}^{3}, A_{3}^{4}, \ldots \text { (ternários) } \\
& A_{4}^{1}, A_{4}^{2}, A_{4}^{3}, A_{4}^{4}, \ldots\left(\text { quaternários) }{ }^{11}\right.
\end{aligned}
$$

Observemos, agora, a lista dos símbolos lógicos:

- Operações lógicas:
i) Negação: ᄀ
ii) Disjunção: $V$
iii) Quantificador existencial: $\exists$

Esses, portanto, são os símbolos que fazem sentido em nossa linguagem. De todo modo, não é o caso que qualquer combinação possível desses símbolos nos dá uma fórmula bem formada. Então, definiremos recursivamente que:

- Uma expressão $\varphi$ é uma fórmula se e somente se:

i) $\varphi$ é da forma $A_{n}^{m}\left(t_{1}, \ldots, t_{n}\right)$, em que $t_{i}, n \geq i \geq 1$ são nomes para indivíduos;

\footnotetext{
${ }^{11}$ Assim como se pode observar, os predicados possuem a forma $A_{n}^{m}$, tal que $m$ é o número que distingue os símbolos de mesma aridade entre si e $n$ é o número da aridade do predicado, isto é, o número de lugares que predicado exige para que fique saturado, completo.
} 
ii) $\varphi$ é da forma $\neg(\psi),(\psi \vee \gamma), \exists x(\psi)$, em que $\psi$ e $\gamma$ são fórmulas e $x$ é pronome.

Neste ponto, sabe-se exatamente quais dentre as expressões possíveis, com base na gramática, fazem sentido. O leitor bem pode ter observado algumas peculiaridades em tudo o que se sucedeu anteriormente: uma delas diz respeito à não presença de todas as operações lógicas a que estamos habituados. A explicação para tal diz respeito à facilidade que uma linguagem oficial árdua e bem regimentada traz ao provar coisas sobre a sintaxe e sobre a própria linguagem em geral. Em contrapartida, para dar exemplos e escrever fórmulas é desejável uma linguagem por demais maleável, contendo, inclusive, todas as operações lógicas. Entenderemos os conectivos restantes como meras abreviações, isto é, como cordialidades da linguagem não oficial.

Outra peculiaridade que se pode notar na linguagem definida é a não presença do símbolo de identidade ou igualdade ${ }^{12}$ na lista de símbolos lógicos, bem como a não presença dos símbolos de função ${ }^{13}$ na lista de símbolos não lógicos. É notório que, principalmente em contextos em se que lida com matemática, a inclusão desses símbolos pode vir a ser muito útil; todavia, não estamos por ora preocupados com questões referentes a matemática e, além disso, o símbolo de igualdade ('=’), é nada mais, nada menos do um predicado binário, ou seja, um tipo de $A_{2}^{m}\left(t_{1}, t_{2}\right)$, sendo $t_{1}$ e $t_{2}$ nomes para indivíduos. Ora, se ele é puramente um predicado binário, por que então colocá-lo na lista de símbolos lógicos? O símbolo de identidade é uma exceção apenas por ser comumente interpretado da mesma forma na grande maioria das vezes; no próprio exemplo dado, $A_{2}^{m}\left(t_{1}, t_{2}\right)$ expressa que $t_{1}$ e $t_{2}$ são termos que denotam o mesmo indivíduo em um domínio de alguma estrutura dada. Todavia, assim como foi explicado, não colocar o símbolo de identidade como primitivo não nos impede de usá-lo com outra abreviação.

Se entendermos a linguagem agora definida como linguagem base $l_{0}$, todas as outras linguagens possíveis serão sempre subconjuntos de $l_{0}$; portanto, para toda linguagem $l_{i}, l_{i} \subseteq$ $l_{0}$. É relevante destacar agora que todas as nossas linguagens, que entenderemos como conjuntos enumeráveis de símbolos não lógicos, serão enumeráveis. Uma linguagem é

\footnotetext{
${ }^{12}$ Neste contexto, 'identidade' e 'igualdade' são sinônimos.

13 Justamente por não fazermos uso dos símbolos de função, definiram-se na gramática os símbolos para constantes, isto é, os nomes próprios. Em linguagens que contêm símbolos de função, podem-se definir as constantes como símbolos de função de zero lugar, zero-ários.
} 
enumerável se e somente se a mesma possui uma função, uma bijeção, com os números naturais.

\subsection{Estruturas e linguagens}

Estando o primeiro ponto esclarecido, devemos voltar nossa atenção para as estruturas, o referente do mundo na lógica clássica de primeira ordem. Antes de definirmos de fato o que é uma estrutura, é necessária uma breve reflexão acerca da natureza disso que se pretende capturar. Uma boa definição precisa evidentemente entregar aquilo que a intuição acerca da coisa nos dá - pelo menos é o que se deve almejar em um primeiro instante, afinal, entender as limitações das intuições também é fator crucial a um discurso filosófico.

A relação que as estruturas possuem com as fórmulas deve ser coerente com a relação que o mundo possui com as frases. Ela deve ser, portanto, uma relação assimétrica, uma relação entre o que se diz e o que é o caso. Perceba que se fala em uma relação assimétrica, pois é o mundo que exerce papel de correção em relação às frases: o mundo é como é; verdadeiro ou falso é o que se diz sobre o mesmo.

Qual é o universo do discurso? Essa pergunta, que a um primeiro olhar mostra-se bastante abstrata, é justamente o que a própria intuição demanda para avaliar a verdade de uma frase em um contexto de linguagem natural. Considere um cenário em que um sujeito entra pela porta e profere:

Todos são ladrões!

Essa frase é verdadeira ou falsa? O leitor provavelmente tem a intuição de responder algo como: bem, depende de quem é 'todo mundo'. Tal é o questionamento que pede pelo domínio do ser, o domínio de existência, o âmbito de aplicação do discurso. Entregar o domínio do ser é dizer sobre o que se pode falar.

O domínio de existência deve ser, mesmo intuitivamente, o primeiro elemento de uma estrutura. Além disso, uma estrutura deve conter os predicados e os indivíduos designados:

$$
\mathfrak{a}=(|\mathfrak{a}|, P, I)
$$


Portanto, uma estrutura a é uma tripla ordenada contendo o domínio de $\mathfrak{a}$, isto é, $|\mathfrak{a}|$, os predicados da linguagem que a interpreta, isto é, $P$, e a denotação dos símbolos de nomes próprios que a interpreta, ou seja, I. Sempre que falamos de uma estrutura particular, falamos de uma $l$-estrutura - ou seja, uma estrutura sempre deve interpretar alguma $l_{i}$. Note que esse é mais um ponto em que a intuição é preservada na formalização, visto que é natural o entendimento de que a estrutura e a fórmula devem se dar em uma mesma linguagem: uma frase como 'o céu é azul' somente pode ser avaliada em relação ao valor de verdade em um contexto, isto é, uma estrutura, em que existe a denotação para o nome 'céu' e a extensão do predicado 'azul'. Perceba que essa frase não possui valor de verdade em um mundo em que 'céu' não denota nada e não existe o predicado 'azul'.

Desse modo, uma estrutura adaptada a uma linguagem, uma l-estrutura, dá-se da seguinte forma:

- $\quad l$-estrutura:

i) Domínio de indivíduos não vazio:

$$
|\mathfrak{a}| \neq \varnothing
$$

ii) Extensões dos símbolos de predicados:

$$
A_{n}^{m a} \subseteq|a|_{1} \times|a|_{2}, \ldots, \times|a|_{n}{ }^{14}
$$

iii) Denotação dos nomes próprios:

$$
a_{n}{ }^{\mathfrak{a}} \in|\mathfrak{a}|
$$

É relevante ressaltar que, ao definirmos uma estrutura como $\mathfrak{a}=(|\mathfrak{a}|, P, I), P$ e $I$ não devem ser entendidos como simples conjuntos, mas como funções. Assim, $P$ é uma função que vai do conjunto dos símbolos de predicado ao conjunto das extensões apropriadas, assim como I é uma função que vai do conjunto dos símbolos de constantes ao conjunto dos indivíduos apropriados. Tendo isso em mente, neste momento pode-se considerar bem definido o que é uma fórmula e, agora, o que é uma estrutura.

Resta-nos, portanto, entender o que significa:

$$
\mathfrak{a} \vDash \varphi
$$

\footnotetext{
${ }^{14}$ Isto é, o produto cartesiano de $n$ cópias de $|\mathfrak{a}|$, tal que $n$ é a aridade de $A_{n}^{m}$ interpretado em a.
} 
O que significa dizer que a estrutura a satisfaz $\varphi$, ou seja, o que significa dizer que $\varphi$ é verdadeira em a? É crucial saber qual é a definição de verdade a que se almeja chegar e, primordialmente, as limitações dessa intuição.

\subsection{As limitações da intuição}

A noção mais intuitiva que normalmente pode-se ter em mente ao se falar de uma definição de verdade é:

$$
T(\ulcorner S\urcorner) \Leftrightarrow S
$$

' $S$ ' é o caso se e somente se $S$. Na medida em que é intuitivo, esse protótipo de definição mostra-se problemático; o problema se respalda justamente no famoso Paradoxo do Mentiroso, o qual se pode formular do seguinte modo:

Esta sentença é falsa.

Note que a questão que envolve tal frase refere-se às suas condições de verdade. Naturalmente, entendemos que, para qualquer frase, a mesma pode ser verdadeira ou falsa. ${ }^{15}$ Consideremos primeiramente, portanto, a hipótese de que tal frase é falsa. Sendo falsa, então o que a mesma diz é o caso e, portanto, deve ser verdadeira. Isso nos leva à segunda hipótese: sendo a frase verdadeira, o que a mesma expressa não é o caso, o que evidentemente nos leva a concluir que deve ser falsa. Nesse ponto, retornamos para a primeira hipótese, e o problema persiste. A questão consiste no fato de que a frase, para ser verdadeira, precisaria ser falsa, o que gera contradição e, além disso, um paradoxo.

Mas o que cria esse paradoxo? Essa é uma questão que pode ser muito difícil de responder, ao menos de forma completa. Um dos pré-requisitos para um paradoxo é gerar um problema que vai além das percepções imediatas. Entretanto, podem-se destacar dois elementos como essenciais para se compreender o Paradoxo do Mentiroso: autorreferência e predicação da verdade.

\section{(autorreferência + predicação da verdade $)=$ paradoxo do mentiroso}

\footnotetext{
${ }^{15}$ E não existe uma terceira opção.
} 
Perceba que na protodefinição apresentada anteriormente, isto é, ' $T(\ulcorner S\urcorner) \Leftrightarrow S$ ', a predicação da verdade está presente. Seria necessário, portanto, apenas um elemento para se gerar autorreferência, a fim de que o paradoxo fosse expresso. Tal elemento será obtido por intermédio do Teorema do Ponto Fixo.

O Teorema do Ponto Fixo está implicitamente presente em outros grandes resultados em lógica, como no próprio Teorema de Gödel e no Teorema da Indefinibilidade da Verdade, demonstrado por Tarski. O mesmo foi isolado e apresentado como resultado independente por Carnap, e pode ser formulado do seguinte modo: se $\gamma(x)$ é uma fórmula, com uma variável livre, de $S$, então existe uma sentença $A$ de $S$, tal que $S \vdash A \Leftrightarrow \gamma(\ulcorner A\urcorner)$.

Isso significa simplesmente dizer que, dado um predicado $\gamma$ qualquer em $S$, para todas as sentenças de $S$, vale que $S$ prova a sentença: $\gamma$ é verdadeiro para $\ulcorner A\urcorner$, sendo ' $\ulcorner A\urcorner$ ' a sentença ' $A$ ' em menção, e não em uso, isto é, trata-se da citação da frase, de um modo de tratar a frase como um objeto, de modo que $\ulcorner A\urcorner$ é um nome próprio de $A$.

Já nesse ponto percebe-se quase de imediato como o predicado de verdade pode ser problemático tendo-se em mente o Teorema do Ponto Fixo, pois, se para toda sentença $A$ e para todo predicado $\gamma$, ambos em $S$, pode-se obter que $S \vdash A \Leftrightarrow \gamma(\ulcorner A\urcorner)$, então o Paradoxo do Mentiroso é facilmente formulável, considerando-se que teríamos um predicado de verdade.

Com essas observações, analisemos agora o problema exposto anteriormente, fazendo a demonstração do Teorema da Indefinibilidade da Verdade, apresentado por Tarski em 1936:

Suponha que $T(x)$ seja uma definição de verdade de $S$ em $S$.

Deste modo:

- $S \vdash T(\ulcorner A\urcorner) \Leftrightarrow A$, para todas as sentenças $A$.

- Pelo Teorema do Ponto Fixo:

Dada uma fórmula qualquer $\gamma(x)$, com uma variável livre, existe uma sentença $B$, tal que $S \vdash B \Leftrightarrow \gamma(\ulcorner B\urcorner)$.

Existe, portanto, uma sentença $B$, tal que $S \vdash B \Leftrightarrow \neg T(\ulcorner B\urcorner)$. Entretanto, pela hipótese inicial: 
- $S \vdash T(\ulcorner B\urcorner) \Leftrightarrow B$

Portanto, por consequência tautológica:

- $S \vdash B \Leftrightarrow \neg B$

$\therefore$ Sendo assim, não pode haver definição de verdade de $S$ em $S$.

A questão agora é lidar com essa limitação. Tal como o teorema demonstra, uma linguagem-objeto que contenha autorreferência e predicação da verdade é capaz de expressar uma forma de Paradoxo do Mentiroso e, por conseguinte, é contraditória, inconsistente. Apesar de ser intuitivo pensar a verdade como $T(\ulcorner S\urcorner) \Leftrightarrow S$, é também intuitivamente inegável, pelo próprio teorema, que esse é um contexto em que a intuição inicial é falha. A forma com que lidaremos com essa questão é a famosa estratégia-padrão, também formulada por Tarski: a introdução de metalinguagens.

Com a introdução da noção de metalinguagem, entender-se-á a verdade de uma teoria em sua metateoria. A verdade lógica, portanto, dá-se na metalógica. Isso significa que o entendimento do significado de 'verdade' de uma teoria deve se dar em um âmbito anterior, em um patamar mais forte, que nos permite expressá-lo sem cairmos em uma instância do Paradoxo do Mentiroso. Essa é a distinção que deve ser feita entre linguagem-objeto e metalinguagem. Tal como o teorema deixa claro, a linguagem-objeto não pode definir o que significa uma sentença, dentro da própria linguagem, ser o caso. Essa concepção deve ser elaborada na metalinguagem, a linguagem capaz de falar sobre a linguagem-objeto.

Note que é no âmbito da metalinguagem que a linguagem-objeto ganha seu significado; é na metalinguagem que se expressa o que ' $\forall$ ', ou ' $\neg$ ' efetivamente significam. É válido ressaltar que, já que estamos, ao menos em um sentido mais fraco, usando a intuição como ponto decisivo acerca dos compromissos ontológicos e metafísicos que estamos tomando - nos moldes do que Kripke argumenta em Naming and necessity [O nomear e a necessidade $]^{16}$ (KRIPKE, 2012, p. 88) -, essa concepção de um patamar anterior para se dar o significado e se poder falar de verdade é bastante razoável, levando-se em conta que em certo sentido entende-se que para se poder falar sobre algo é necessário um âmbito anterior em que se legisla seu significado.

\footnotetext{
${ }^{16}$ Enfatizando, mais uma vez, que entendemos 'intuição' em um sentido mais fraco do que Kripke. Trata-se não de uma intuição a priori, mas de um tipo de intuição empírica, a posteriori.
} 
Todavia, a questão que de imediato se segue de tudo o que foi dito acima é o problema relacionado à infinitude das concepções semânticas de verdade em ciências formais: a hierarquia das metalinguagens - ou melhor, a infinitude das hierarquias de metalinguagens. Assim como explicado, deve-se entender a verdade de uma teoria em sua metateoria. O ponto relacionado às hierarquias de metalinguagens diz respeito ao entendimento da verdade dessa metateoria, ou seja, seria necessária uma meta-metateoria, ad infinitum.

Considere a teoria $B$. A verdade de $B$ é dada na metateoria $B^{\prime}$, assim como a verdade de $B^{\prime}$ é expressa na meta-metateoria $B^{\prime \prime}$, e assim por diante:

$$
\ldots \curvearrowleft B^{\prime \prime \prime \prime} \curvearrowleft B^{\prime \prime \prime} \curvearrowleft B^{\prime \prime} \curvearrowleft B^{\prime} \curvearrowleft B
$$

A pergunta que o leitor pode se fazer neste momento é: qual é a legitimidade dessa infinitude? Até que ponto essa infinitude é propriamente lógica? Evidentemente, tal questionamento é genuíno, afinal, pensar-se que para se entender a verdade de uma teoria é necessário um âmbito anterior, ou seja, uma metateoria, e que a verdade dessa metateoria não estaria bem fundada nos leva a questionar se efetivamente toda essa infinitude possui um caráter de fato lógico. De certo modo, parece que o que se está fazendo é apenas postergar infinitamente essa fundamentação da verdade em hierarquias de metalinguagens. Talvez a estratégia das metalinguagens seja mais um bom exemplo de como a intuição pode ser falha, já que, como se argumentou, é intuitivo pensar em metaníveis de linguagens.

Entretanto, um ponto a ser esclarecido e que pode vir a ser decisivo acerca de toda essa problemática, no que se refere à infinitude das metalinguagens, é a diferença entre a tentativa de redução e de análise de uma teoria. Quando se diz que uma linguagem-objeto consistente não pode ser capaz de expressar sua verdade, não se está buscando reduzir sua noção de verdade a um metanível. O que se tem em mente ao falar de metalinguagens é que para analisar ou compreender a noção de verdade é preciso estabelecer critérios anteriores que nos ofereçam legitimidade para todo o debate acerca da verdade.

Uma redução seria evidentemente problemática, pois implicaria que nunca existiria uma redução última que, de fato, pudesse lidar com a verdade. A infinitude das hierarquias de metalinguagens, pensadas enquanto redução da verdade de um nível para um metanível, é insatisfatória, pois desejaríamos que fosse possível terminar a redução e, de uma vez por 
todas, entender o que significa, finalmente, 'verdade'. Sabemos que isso, ao menos nos moldes do que foi apresentado, não é possível. De todo modo, não se almeja reduzir a noção de verdade a esse metanível, mas sim analisá-la.

Além disso, faz sentido pensar que é preciso um âmbito anterior em que se estabelece o critério do que se pretende fazer. Igualmente, a verdade desse metanível não pode ser reduzida, mas pode ser compreendida em um nível ainda anterior. A grande questão que se poderia colocar é aquela de que não é razoável pensar em um patamar último de compreensão, diferentemente de quando se tem em pauta a proposta de redução, pois sempre que lidamos com um nível de discurso particular é necessário um patamar anterior para que esse nível particular faça sentido. Da mesma forma, seria honesto argumentar que a verdade também precisa ser sempre analisada nesse nível mais básico, mais fundamental.

O ponto é que nenhuma linguagem é objeto ou metalinguagem em si mesma; esses são papéis desempenhados em um dado contexto. Uma metalinguagem pode exercer o papel de linguagem-objeto no instante em que se almeja analisar sua concepção de verdade. Não existe portanto, stricto sensu, uma metalinguagem de uma metalinguagem, pois, para que a mesma seja analisada em algum sentido por intermédio da noção dos metaníveis, a linguagem em pauta precisa exercer o papel de linguagem-objeto.

Talvez a distinção entre redução e análise da verdade de uma teoria em sua metateoria não seja suficiente para que a questão da infinitude das hierarquias de metalinguagens mostrese superada e devidamente explicada. De todo modo, o que se ganha com tal distinção é ao menos uma nova oportunidade. Afinal, entender tais coisas nos critérios de redução seria errado; por conseguinte, mostrar que não é isso que estamos fazendo pode trazer um novo tipo de reflexão para um ponto que, sem olhares atentos, mostra-se trivialmente incorreto. Lidando com todo o peso das limitações que as intuições originais e derivadas nos entregam, apresentemos, nos moldes de Tarski, a definição semântica de verdade.

\section{DEFINIÇÃO DE VERDADE}

Seja $l_{i}$ uma linguagem particular e a, uma $l_{i}$-estrutura. Dada uma sentença $\varphi$ em $l_{i}$, o que significa $\mathfrak{a} \vDash \varphi ?^{17}$

\footnotetext{
${ }^{17} \mathrm{O}$ que significa dizer que $\varphi$ é verdadeira na interpretação, na estrutura $\mathfrak{a}$.
} 
- Definição por indução na complexidade de $\varphi$ :

1) Se $\varphi$ é atômica, ou seja, é da forma $A_{n}^{m}\left(t_{1}, \ldots, t_{n}\right)^{18}$, tal que $t_{1}, \ldots, t_{n}$ são nomes próprios, então $\mathfrak{a} \vDash \varphi$ se e somente se $\left(t_{1}^{\mathfrak{a}}, \ldots, t_{n}^{\mathfrak{a}}\right) \in A^{\mathfrak{a}}$.

Tratando-se do caso da sentença atômica, ela é verdadeira na estrutura em questão apenas no caso em que os indivíduos que os nomes próprios denotam nessa estrutura encontram-se na extensão do predicado $n$-ário denotado pelo símbolo de predicado.

2) Se $\varphi$ é uma negação, ou seja, é da forma $\neg(\psi)$, então $\mathfrak{a} \vDash \varphi$ se e somente se não é o caso que $\mathfrak{a} \vDash \psi ;{ }^{19}$

3) Se $\varphi$ é uma disjunção, ou seja, é da forma $(\psi \vee \gamma)$, então $\mathfrak{a} \vDash \varphi$ se e somente se $\mathfrak{a} \vDash \psi$ ou $\mathfrak{a} \vDash \gamma \cdot{ }^{20}$

Resta-nos agora considerar o último caso no que se refere às possibilidades de $\varphi$, ou seja, o caso em que $\varphi$ é uma fórmula existencial: e se $\varphi$ é um existencial, isto é, da forma $\exists x(\psi)$ ? Nesse caso, $\mathfrak{a} \vDash \varphi$ se e somente se...?

Muito provavelmente, a primeira resposta que o leitor pode elaborar para essa questão é a chamada abordagem substitucional. Basicamente, essa estratégia consiste em dizer que $\mathfrak{a} \vDash$, se e somente se, para algum indivíduo $\alpha \in|\mathfrak{a}|, \mathfrak{a} \vDash \exists x(\psi)$, quando $x$ denota $\alpha$. Um modo de traduzir isso para nosso linguajar oficial, levando-se em conta que a frase acima não pode ser uma fórmula, pois $\alpha$ não é um nome do indivíduo, mas sim o próprio indivíduo, seria:

$\mathfrak{a} \vDash \varphi$ se e somente se, para algum nome próprio $c$ em $l_{i}$, vale que $\mathfrak{a} \vDash \psi_{x[c]}{ }^{21}$

\footnotetext{
${ }^{18}$ Deve-se ressaltar que não estamos considerando a identidade e símbolos funcionais, apesar de que, como dito, a identidade possa ser entendida como algum predicado binário. Portanto, nessas restrições toda sentença atômica tem a forma $A_{n}^{m}\left(t_{1}, \ldots, t_{n}\right)$ para algum predicado não lógico $A$ e constantes $t_{I}$.

${ }^{19} \mathrm{Tal}$ como fica evidente, o passo indutivo é o entendimento de que para tudo o que é menos complexo do que $\varphi$ a definição é válida.

${ }^{20}$ Já nesse ponto, o fato de termos definido uma linguagem oficial com menos recursos e árdua mostra-se proveitoso ao entrarmos no âmbito da metalógica. Perceba que a própria definição de verdade torna-se mais direta e simples ao ter de lidar com menos operações lógicas, afinal, trata-se de uma definição por indução na complexidade de $\varphi$; portanto, menos casos para $\varphi$ significam menos passos na definição.

${ }^{21}$ Isto é, com $c$ instanciado em todas as ocorrências de $x$ na fórmula em questão.
} 
A primeira ressalva que surge com a proposta substitucional é que não existem garantias de que o indivíduo $\alpha_{i}$ que irá realizar, tornar verdadeira, a fórmula $\psi$ possui um nome. É natural que isso, para a intuição corriqueira, mostre-se estranho, levando-se em conta que é difícil considerar que se trata de um objeto sem nome e que, de certo modo, não poderia ser colocado no discurso. Apesar de o símbolo ' $\alpha$ ' ser um grafo tão bom quanto ' $c$ ' ou quanto os símbolos que na gramática se usam para nomes próprios, ' $\alpha$ ' possui um papel totalmente distinto; é um símbolo que, na realidade, faz parte da metalinguagem e denota o objeto em si. Uma frase como ' $\exists \alpha P \alpha$ ' mistura dois níveis de linguagem, e não pode ser efetivamente uma fórmula.

Nesse caso, poder-se-ia então considerar a ideia de estender a interpretação de tal modo que todo indivíduo do domínio de existência seja denotado por um símbolo de constante. No contexto em que isso é realizado, o problema anterior mostra-se superado, e torna-se razoável a proposta substitucional. O problema é que tal medida em geral não é possível, pois poderíamos estar lidando com um domínio não enumerável.

Consideremos uma estrutura $\mathfrak{a}_{\mathbb{R}}$ que tem como domínio $\left|\mathfrak{a}_{\mathbb{R}}\right|=\{\mathbb{R}\}$, ou seja, o conjunto dos números reais. Definiu-se que um conjunto é enumerável se e somente se existe uma função, que é uma bijeção, com os números naturais. Nossa linguagem é enumerável; o conjunto de símbolos para constantes é enumerável. Para que fosse possível adicionar uma constante para cada elemento da estrutura em questão, seria necessária uma função sobrejetora tal que $f: \mathbb{N} \rightarrow \mathbb{R}$, o que, pelo Teorema de Cantor, sabe-se não ser possível.

O Teorema de Cantor afirma que a cardinalidade do conjunto das partes de $X$, isto é, $P(X)$, é estritamente maior que $X$, seja $X$ finito ou infinito: ${ }^{22}$

$$
|X|<|P(X)|
$$

Portanto, não existe uma função sobrejetora tal que $f: \mathbb{N} \rightarrow P(\mathbb{N})^{23}$, ou seja, não existe uma função sobrejetora tal que $f: \mathbb{N} \rightarrow \mathbb{R}$. Façamos uma breve demonstração do Teorema de Cantor:

- Não existe uma função sobrejetora tal que $f: X \rightarrow P(X)$.

\footnotetext{
${ }^{22}$ Quando se trata de conjuntos finitos, isso é facilmente observável; a cardinalidade do conjunto das partes de $X$ sendo $X$ finito, é $|P(X)|=2^{|X|}$. A questão, portanto, dá-se no caso de conjuntos infinitos.

${ }^{23}$ É válido ressaltar que o conjunto $\mathbb{R}$ é comumente definido como $P(\mathbb{N})$.
} 
1) Suponha que existe $f: X \rightarrow P(X)$;

2) Considere o conjunto $Y$, tal que $Y=\{x \in X \mid x \notin f(x)\}$;

- Note que:

3) $Y \in P(X)$;

4) $Y \subseteq X$

- Suponha agora que $f(a)=Y$, para algum $a \in X$ qualquer.

5) $a$, que pertence a $X$, pertence a $f(a)$ ?

6) Sabe-se que $a \in f(a) \equiv a \in Y \equiv a \in X \wedge a \notin f(a)$.

$\therefore a \in f(a) \Leftrightarrow a \notin f(a)$

Além de mostrar que sempre existe um desencontro entre um conjunto qualquer e o conjunto de suas partes, o Teorema de Cantor nos entrega um peso ontológico muito maior: existe uma infinidade de infinitos:

$$
|\mathbb{N}|<|P(\mathbb{N})|<|P(P(\mathbb{N}))|<|P(P(P(\mathbb{N})))|<\cdots
$$

Existe, portanto, um primeiro infinito, mas não um último. Voltando a nossa questão inicial, isto é, a de dar nomes para todos os indivíduos de uma estrutura $\mathfrak{a}_{\mathbb{R}}$ com domínio: $\left|\mathfrak{a}_{\mathbb{R}}\right|=\{\mathbb{R}\}$, isso nos leva à conclusão de que não teríamos símbolos de constantes suficientes para completar essa tarefa, já que possuímos um estoque infinito, enumerável, contável com $\mathbb{N}$ e, pelo teorema, não existe uma atribuição de um para um de $\mathbb{N}$ para $P(\mathbb{N})$, ou simplesmente de $\mathbb{N}$ para $\mathbb{R}$. Assim, quando o domínio da interpretação é não enumerável, a estratégia substitucional falha.

Para lidar com mais essa questão de infinitude, alguns caminhos mostram-se possíveis; dentre eles, um em particular merece destaque. Já que nossa linguagem é enumerável e possui apenas um estoque enumerável de símbolos e, por conseguinte, de símbolos para constantes, poder-se-ia alterar a linguagem tornando-a não enumerável e, portanto, possibilitando a atribuição de um para um dos nomes próprios para os indivíduos de um domínio, inclusive no caso dos de cardinalidades não enumeráveis. Isso não somente pode ser feito como, em dados contextos, é por motivos técnicos recomendável. ${ }^{24}$ Fazer essa alteração significa mudar o entendimento do que é, ou melhor, de como deveria ser uma linguagem.

\footnotetext{
${ }^{24}$ Evidentemente, em contextos mais voltados ao âmbito matemático.
} 
Uma linguagem não enumerável acarreta um peso ontológico significativo. A mudança desse conceito pode ser muito complicada, principalmente em âmbitos em que o ponto que move a investigação é a questão da verdade, pois nos obriga a compactuar, por exemplo, com que uma linguagem não pode ser listada, nos moldes do que foi feito. Dessa forma, tampouco é possível saber, do mesmo modo que a maneira já apresentada nos permite, o que é e o que não é exatamente um símbolo de constante. Além do mais, nada nos impede, em princípio, de nos depararmos com alguma estrutura com domínio maior do que $P(\mathbb{N})$, fazendo com que mais uma vez a infinitude de infinitos inviabilize o entendimento de 'verdade'.

É justamente o fato de podermos, ainda assim, nos deparar com domínios maiores do que o infinito, já não enumerável, da linguagem-base que nos leva a afirmar que essa modificação, na realidade, significa o total desprendimento para com a visão de que a linguagem tem um tamanho-limite, ou melhor, de que existe uma linguagem-limite. A definição da linguagem já feita possui esse fator limitante, $l_{0}$, com seu tamanho infinito, porém, enumerável. Mesmo que a linguagem natural seja entendida como tendo um tamanho infinito apenas potencial e não atual, é razoável defender que a mesma possui esse fator limitante que é enumerável. O salto para o não enumerável significa, na prática, o salto para o fim da linguagem-base ou, pelo menos, de seu papel limitador absoluto.

Uma linguagem não enumerável pode ser algo muito distante de seu correlato, que se pretende com estas investigações trazer à luz: a linguagem natural. Nossa investigação é acerca da verdade, especificamente de uma verdade que se dá por meio da linguagem. Essa estratégia, mesmo que legítima, pode acabar nos levando a lugares e respondendo a questões um pouco distantes, pelo menos intuitivamente, de tudo o que de fato nos motivou até aqui.

A estratégia de que faremos uso para o caso da quantificação é uma estratégia que lida com o problema dos nomes de forma mais indireta. Levando-se em conta que estender a linguagem $l_{i}$ particular acrescentando, de uma só vez, uma constante para cada indivíduo do domínio na maioria das vezes não pode ser feito sem transformar a linguagem base $l_{0}$ em não enumerável, consideraremos um indivíduo qualquer particular $\alpha_{i}$, tal que $\alpha_{i} \in|\mathfrak{a}|$, sendo a a $l_{i}$-estrutura em questão. Desse modo, poder-se-iam estender a linguagem e a interpretação de tal maneira a atribuir somente a esse indivíduo um nome, e, então, consideraríamos todas as extensões possíveis da linguagem e da interpretação pelo acréscimo de apenas um nome novo e pela atribuição a ele de uma denotação. 
Considere que na estrutura a o indivíduo $\alpha$ satisfaz $\psi(x)$. Ao escrevermos $\mathfrak{a} \vDash \psi_{x[\alpha]}$, estamos dizendo que, se considerássemos a extensão de $l_{i}$, isto é, $l_{i} \cup\{c\}$, obtida pelo acréscimo de um nome novo $c$ à linguagem $l_{i}$, e se dentre todas as extensões de a nessa interpretação estendida considerarmos a interpretação $\mathfrak{a}_{\alpha}^{c}$ que denota a 'c' ' $\alpha$ ', então $\psi(c)$ seria verdadeira.

Fazendo-o de forma mais rigorosa:

- E se $\varphi$ é um existencial, isto é, da forma $\exists x(\psi)$ ? Nesse caso, $\mathfrak{a} \vDash \varphi$ se e somente se...?

- Considere uma nova constante ' $c$ '.

1) $\mathfrak{a}_{\alpha}^{c}$ é a estrutura obtida a partir de a pela atribuição de ' $\alpha$ ' a ' $c$ ', tal que $\alpha \in|\mathfrak{a}|$. Portanto:

2) $\mathfrak{a} \vDash \varphi$ se e somente se existe um indivíduo $\alpha$ no domínio da estrutura, tal que $\mathfrak{a}_{\alpha}^{c} \vDash \psi_{x[c]}$.

\section{CONSIDERAÇÕES FINAIS}

Nessas condições, pode-se finalmente entender o que significa dizer que uma fórmula é verdadeira em uma estrutura. Naturalmente, o objetivo sempre foi apresentá-lo de tal modo que seu desenvolvimento trouxesse luz para a questão da verdade de que tanto se falou no decorrer deste texto. É sem qualquer relutância que podemos afirmar que efetivamente o esclarecimento da verdade lógica, nesse âmbito semântico, reflete o que a intuição, tanto pré quanto pós-teórica, nos evoca. Olhar para tal resultado enquanto número frio é ignorar o caminho que se percorreu para que o mesmo agora estivesse aqui.

De fato, a ontologia e o respaldo metafísico - que a concepção de verdade que se buscou formular desde o início apresenta - fornecem, com esses resultados, um bom parâmetro instrumental e conceitual para que o debate filosófico possa caminhar de tal forma que fique claro onde se está e para onde se dirige. Sem sombra para dúvidas, é o caso que essa concepção semântica de verdade, a qual se dá por meio de uma linguagem, de estruturas e fórmulas, captura e explica a visão aristotélica de verdade; temos em mãos um modo de obter clareza e precisão inquestionáveis, não somente para que a 
vantagem dessa visão aristotélica fique evidente, mas principalmente para que seus problemas estejam ainda mais expostos.

O filósofo brasileiro Newton da Costa, outra vez em Ensaio sobre os fundamentos da lógica, diz que,

Em síntese, a lógica se funda numa concepção metafísica de mundo. Os princípios da identidade, da contradição e do terceiro excluído, por exemplo, constituem, primeiramente, leis do ser. Decorrem de uma doutrina estática do real: o ser é fixo e permanente; daí ser sempre idêntico a si mesmo (princípio da identidade), não pode ser e não ser ao mesmo tempo (lei da contradição) e deve ser ou não ser, sem outra alternativa (tertium non datur). Tais princípios constituem leis ontológicas e, secundariamente, normais lógicas. (DA COSTA, 1994, p. 77)

Tem-se, então, uma teoria da verdade que parece se comprometer com a metafísica aristotélica, o que aqui sempre foi o foco, sempre foi aonde se pretendeu chegar. Entretanto, assim como já dito, isso não pode esconder o peso das decisões tomadas no caminho. A questão da infinitude na concepção semântica de verdade em ciências formais apenas reflete a própria infinitude, que muitas vezes não é tão estranha, estando mesmo presente em qualquer nível de um sistema formal. São infinitos símbolos, infinitas fórmulas, infinitas validades. Esperar que a infinitude, ao nível metateórico, não seja uma questão seria esperar um comportamento totalmente incoerente com a própria natureza da lógica.

Não se trata, portanto, de um problema que surge inesperadamente ao se buscar uma compreensão do nível fundacional da concepção de verdade lógica, o que, por sua vez, de maneira alguma suspende ou mesmo justifica as questões abordadas no decorrer do texto. $\mathrm{O}$ ponto é que não se trata da questão da infinitude nas concepções semânticas de verdade da lógica, mas sim da infinitude da própria lógica, das próprias ciências formais. Afirmar que essa infinitude é ela mesma lógica ou não muito provavelmente seria dizer mais do que se pode; entretanto, é evidente que a infinitude é ela mesma um ingrediente da lógica que não pode ser ignorado. 


\section{REFERÊNCIAS}

AYER, Alfred Jules. Language, truth, and logic. $2^{\text {nd }}$ ed. London: Gollancz, 1956.

BÉZIAU, Jean-Yves. Universal logic. In: Logica '94 - Proceedings of the 8th International Symposium. T. Childers \& O. Majer (eds.). Prague, 1994. p. 73-93.

BOOLOS, George Stephen; BURGESS, John Patton; JEFFREY, Richard Carl. Computabilidade e lógica. São Paulo: Unesp, 2012.

DA COSTA, Newton. Ensaio sobre os fundamentos da lógica. 2 ed. São Paulo: Hucitec, 1994.

FREGE, Gottlob. The thought: a logical inquiry. Mind, JSTOR, v. 65, n. 259, 1956, p. 289-311.

HEGEL, Georg Wilhelm Friedrich. Introdução à história da filosofia. In: Os Pensadores: Hegel. São Paulo: Nova Cultural, 1988.

HRBACEK, Karel. Introduction to set theory. 3 ed. Nova York: Marcel Dekker, 1999.

KRIPKE, Saul Aaron. O nomear e a necessidade. Lisboa: Gradiva, 2012.

PRIEST, Graham. In contradiction. 2 ed. Oxford University Press, 2006. 